\title{
Aerobic Conversion of Glycerol to 2,3-Butanediol by a Novel Klebsiella variicola SRP3 Strain
}

\author{
Md. Shafiqur Rahman', Zhongshun Yuan², Kesen Ma ${ }^{3}$, Chunbao (Charles) Xu² and Wensheng Qin ${ }^{1 *}$ \\ ${ }^{1}$ Department of Biology, Lakehead University, Canada \\ ${ }^{2}$ Institute for Chemicals and Fuels from Alternative Resources (ICFAR), Western University, London, Canada \\ ${ }^{3}$ Department of Biology, University of Waterloo, 200 University Avenue West, Waterloo, Ontario, Canada
}

\begin{abstract}
The manufacture of biodiesel generates about $10 \%$ crude glycerol as a core by- product. This research is to identify novel bacterial strains which are capable of efficiently converting glycerol aerobically, and improve the strains for large scale production of value-added products. The production of a major product 2,3-butanediol $(2,3-$ BD) from glycerol as a sole carbon source by the newly isolated Klebsiella variicola SRP3 are reported in a series of batch processes under aerobic condition. This study also compares the bacterial cell biomass, bio-products and glycerol dehydrogenase (GDH) enzyme production of $K$. variicola SRP3 isolated from paper mill waste when grown in aerobic condition. The incubation temperature, $\mathrm{pH}$, glycerol concentration and nitrogen sources are the most important factors ruling the glycerol dehydrogenase. Acidic initial $\mathrm{pH}(\mathrm{pH} 5.0)$ led to enhanced GDH activity $(558.2$ $\mu \mathrm{mol} / \mathrm{min} / \mathrm{mg}$ protein), yielding $25.33 \mathrm{~g} / \mathrm{L} \mathrm{2,3-BD,} 7.6 \mathrm{~g} / \mathrm{L} \mathrm{1,3-PDO}$ and $2.2 \mathrm{~g} / \mathrm{L}$ acetoin from $50.0 \mathrm{~g} / \mathrm{L}$ glycerol. In our aerobic batch culture the mutated strain $K$. variicola SRM3 exhibited 1.3 fold increased GDH activity of 721.5 units $/ \mathrm{mg}$ protein from 558.2 units $/ \mathrm{mg}$ protein, yielding $29.87 \mathrm{~g} / \mathrm{L}$ 2,3-BD, $7.08 \mathrm{~g} / \mathrm{L} \mathrm{1,3-PDO}$ and $2.02 \mathrm{~g} / \mathrm{L}$ acetoin from $50.0 \mathrm{~g} / \mathrm{L}$ glycerol. In our report, the optimal conditions for maximal GDH enzyme activity were defined, and 0.79 $\mathrm{g} / \mathrm{g}$ product yield was achieved by the muted strain $K$. variicola SRM3, which is the highest amount obtained from glycerol as a sole carbon source until now. The research has for the first time proved that this $K$. variicola species can efficiently convert glycerol.
\end{abstract}

Keywords: Glycerol dehydrogenase; Glycerol; 2,3-Butanediol; 1,3-Proponediol; Klebsiella variicola

\section{Introduction}

Increasing demand and the rising cost of fossil fuels, as well as a concern for global climate change have shifted global efforts to utilize renewable resources for the production of a 'greener' energy replacement [1]. One major obstacle facing the development of biodiesel is the high volume of crude glycerol $(10 \% \mathrm{v} / \mathrm{v})$ generated from transesterification process. Generally speaking, there is a lack of microorganisms which can produce sufficient amounts of glycerol degrading enzymes to efficiently convert crude glycerol to value-added bio-products. The new isolate of bacteria permits screening, isolation and over expression of enzyme to help overcome these challenges. Several microorganisms have been found to produce a variety of enzymes for the biodegradation of glycerol [2]. Primarily, glycerol dehydrogenase (GDH) is an important cellbound (intracellular) enzyme of bacteria that can convert glycerol to dihydroxyacetone (DHA) and other products under aerobic condition $[1,3,4]$. Klebsiella pneumoniae has well developed metabolic pathways for glycerol metabolism. In aerobic condition, K. pneumoniae utilizes glycerol through complex oxidative and reductive pathways (Figure 1) [5]. In the oxidative pathway glycerol is dehydrogenated by an $\mathrm{NAD}^{+}$-dependent glycerol dehydrogenase to dihydroxyacetone (DHA) by generating reducing equivalent $\mathrm{NADH}_{2}$. Afterwards, DHA is then further metabolized to various products viz., 2,3-BD, ethanol, acetic acid through pyruvate [6,7]. The reducing equivalent NADH generated from oxidative pathway by GDH directly influenced on the production of 1,3-PDO under aerobic condition of glycerol metabolism $[2,6]$. However, in the parallel reductive branch, glycerol is $1^{\text {st }}$ dehydrated to 3-hydroxypropionaldehyde (3-HPA) by glycerol dehydratase, and it is then reduced to 1,3-PDO by NADH-linked 1,3-PDO dehydrogenase, thereby regenerating $\mathrm{NAD}^{+}[4,6,7]$. In K. pneumoniae, the generation of $\mathrm{NAD}^{+}$from the reductive pathway is utilized by the $1^{\text {st }}$ enzyme GDH of the oxidative pathway [2].
Acetoin and 2,3-BD are two significant biorefinery platform chemicals. As an important physiological metabolic product acetoin can be produced by fermentation of sugar and other carbon sources $[8,9]$. Acetoin is widely used in food, flavour, cosmetics, and chemical synthesis [10]. The 2,3-butanediol, a reduced form of acetoin, is widely

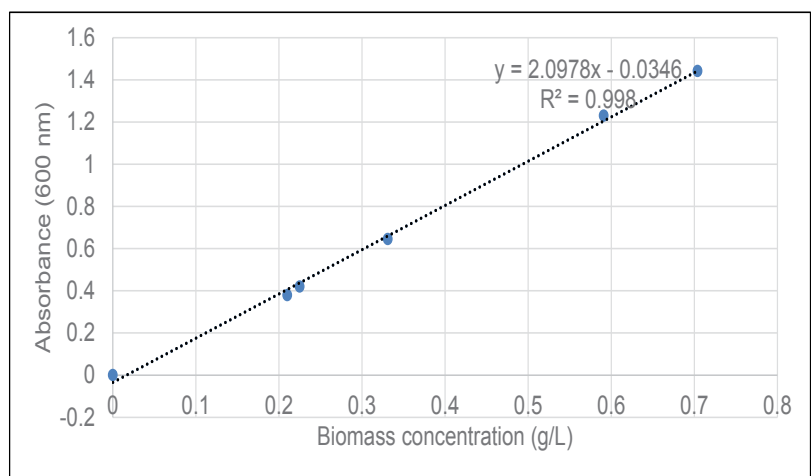

Figure 1: Standard curve for conversion of absorbance to dry cell weight (DCW) of bacteria.

*Corresponding author: Wensheng Qin, Department of Biology, Lakehead University, Canada, Tel: +1 807-343 8467, Fax: 807-346 7796; E-mail: wqin@lakeheadu.ca

Received August 25, 2015; Accepted September 18, 2015; Published September 25, 2015

Citation: Rahman MS, Yuan Z, Ma K, Xu CC, Qin W (2015) Aerobic Conversion of Glycerol to 2,3-Butanediol by a Novel Klebsiella variicola SRP3 Strain. J Microb Biochem Technol 7: 299-304. doi:10.4172/1948-5948.1000229

Copyright: (c) 2015 Rahman MS, et al. This is an open-access article distributed under the terms of the Creative Commons Attribution License, which permits unrestricted use, distribution, and reproduction in any medium, provided the original author and source are credited. 
used as an antifreeze agent, lubricant, liquid fuel or fuel additive and a precursor of many synthetic materials including polymers and resins [11]. It can also be used for the manufacturing of printing ink, perfumes and fumigants, polymer, pharmaceutical carrier, moistening and softening agents, and reagent in different asymmetric chemical synthesis [12]. The 2,3-BD is a physiological metabolic product of the acetoin metabolic pathway in bacteria, and can be transformed to each other by 2,3-butanediol dehydrogenase in cells [10]. There are three key enzymes comprising catabolic $\alpha$-acetolactate synthase, $\alpha$-acetolactate decarboxylase, and 2,3-butanediol dehydrogenase, also called acetoin/ diacetyl reductase are liable for the 2,3-BD biosynthesis [13,14].

A simple organic chemical 1,3-PDO obtained from microbial fermentation of glycerol is one of the high value products that has several interesting applications. The potential uses of this chemical are in the preparation of plastic, laminates, UV cured coating, adhesives material, anti-freeze, and it is also used as a solvent. The 1,3-propanediolbased polymers possess some better features than that generated from 1,2-PDO, butanediol or ethylene glycol. Now, 1,3-PDO is used to produce poly-trimethylene terephthalate (PTT), a biodegradable polyester which is widely used in carpet and textile manufacturing [15]. The precursor 1,3-PDO of PTT is produced through chemical synthesis [16] and fermentatively from glucose by microbes [17]. The joint venture company DuPont and Tate \& Lyle, Loudon, Tennessee, USA have developed a proprietary process to produce 1,3-PDO using corn glucose instead of petroleum-based feed stocks. Nowadays, the anaerobic fermentation is the most promising option for bioconversion of glycerol by Klebsiella, Citrobacter, Clostridium, Lactobacillus and Bacillus [18].

Several Klebsiella strains except K. variicola have already been isolated which are able to ferment glycerol and the main product was 1,3-propanediol (1,3-PD), while 2,3-BD was in minor quantity along with other products $[15,19-21]$. In our research article, we deal with the metabolic aspects of aerobic batch fermentation of glycerol by a novel strain $K$. variicola, and the effect of fermentation kinetics, and the conditions providing the gain of over expression of GDH. In this study, we report a major product of 2,3-BD and turning 1,3-PDO into minor from glycerol as a sole carbon source by an isolate SRP3 identified as $K$. variicola and its mutant SRM3. The fermentation kinetics of batch culture processes was studied in detail, and the conditions providing the gain of increased activity of GDH were evaluated. As a result, the growth rate, glycerol uptake rate, and the product concentrations were greatly enhanced in K. variicola and its mutant.

\section{Materials and Methods}

\section{Isolation and identification of bacterial strain}

The paper mill waste samples for isolation of glycerol-degrading bacteria were obtained from a paper mill in Thunder Bay, Ontario, Canada. About $5 \mathrm{~g}$ of sample was inoculated into $100 \mathrm{ml}$ minimal salt (MS) broth medium supplemented with $100 \mathrm{~g} / \mathrm{L}$ glycerol in a $250 \mathrm{ml}$ Erlenmeyer flasks, and incubated at $35^{\circ} \mathrm{C}$ with shaking $(200 \mathrm{rpm})$ for $48 \mathrm{~h}$. MS medium containing pure glycerol as a sole carbon source and comprised of (per L): glycerol (100 g, 99.0\% analytical grade, Sigma), $\mathrm{NaNO}_{3}(0.1 \mathrm{~g}), \mathrm{K}_{2} \mathrm{HPO}_{4}(0.1 \mathrm{~g}), \mathrm{KCl}(0.1 \mathrm{~g})$, and $\mathrm{MgSO}_{4} .7 \mathrm{H}_{2} \mathrm{O}(0.05 \mathrm{~g})$. Following incubation, inoculum from flasks showing growth was plated onto MS agar plates containing $5 \%$ analytical grade glycerol, and pure isolates were preserved at $4^{\circ} \mathrm{C}$.

The greatest glycerol utilizing (GDH enzyme producing) isolate SRP3 was identified using 16S rRNA sequencing confirmed by its phenotypic and physiological characteristics. To amplify the $16 \mathrm{~S}$ rDNA fragments universal primers designed within conserved regions of the $16 \mathrm{~S}$ rDNA for Eubacteria were used: HAD-1 (5'-GACTCCTACGGGAGGCAGCAGT) and E1115R (5'-AGGGTTGCGCTCGTTGCGGG), they amplified a $796 \mathrm{bp}$ fragment. The PCR product was purified with Clean-up kit (FroggaBio, Canada) and sequenced (Eurofins MWG Operon, US). Sequencing result was inputted online in the nucleotide blast tool through the NCBI database (http://blast.ncbi.nlm.nih.gov/) to identify the possible genus. The 16S rRNA sequence of isolated strain has been submitted to the GenBank under accession numbers KR092086. To identify the species of the genera the morphological and physiological characteristics were determined [22-24].

\section{Fermentation medium and culture conditions}

The strain was maintained at $4^{\circ} \mathrm{C}$ (sub-cultured every month) and one set stored at $-80^{\circ} \mathrm{C}$ with $20 \%(\mathrm{w} / \mathrm{w})$ glycerol added. The inoculum cultures were grown at $35^{\circ} \mathrm{C}$ and at $200 \mathrm{rpm}$ under aerobic conditions in the Luria-Bertani (LB) broth medium (yeast extract, $5 \mathrm{~g} / \mathrm{L}$; peptone $10 \mathrm{~g} / \mathrm{L} ; \mathrm{pH}$ 7.0). In case of enzyme assay, different $\mathrm{pH}$, incubation temperatures $\left(25,30,35\right.$ and $\left.40^{\circ} \mathrm{C}\right)$, and concentrations of glycerol, yeast extract and peptone were maintained in the culture medium. When indicated, the medium was supplemented with specified concentration of different nitrogen sources. The $\mathrm{pH}$ of the medium was adjusted with $1 \mathrm{M} \mathrm{NaOH}$ or $1 \mathrm{M} \mathrm{HCl}$, depending on the experiment. Batch fermentations were carried out in $125 \mathrm{ml}$ Erlenmeyer flasks containing $50 \mathrm{ml}$ fermentation medium, with $50 \mu \mathrm{l}$ of 20 hours culture, and incubated at $35^{\circ} \mathrm{C}$ under aerobic condition at $200 \mathrm{rpm}$ using rotary shaker (New Brunswick Scientific, C25 incubator shaker, NJ, USA). The fermentation medium containing glycerol as a sole carbon source and comprised of (per L): $\mathrm{NaNO}_{3}(0.1 \mathrm{~g}), \mathrm{K}_{2} \mathrm{HPO}_{4}(0.1 \mathrm{~g}), \mathrm{KCl}(0.1 \mathrm{~g})$, and $\mathrm{MgSO}_{4} .7 \mathrm{H}_{2} \mathrm{O}(0.05 \mathrm{~g})$, glycerol $(50.0 \mathrm{~g})$, yeast extract $(2.5 \mathrm{~g})$ and peptone $(5.0 \mathrm{~g})$

\section{Optimization of fermentation process and medium components}

Cells from slant cultures were inoculated into a LB broth medium to prepare the seed culture. After $20 \mathrm{~h}$ incubation at $35^{\circ} \mathrm{C}$ under aerobic condition at $200 \mathrm{rpm}$ using rotary shaker, $50 \mu$ of grown seed culture was inoculated into appropriate medium for optimization growth conditions including incubation temperature and time, medium initial $\mathrm{pH}$, glycerol concentration, and nitrogen sources. All the optimization parameters were performed in triplicates.

\section{Enzyme activity assay and protein determination}

Cells from $1 \mathrm{ml}$ of aerobic cultures $\left(\mathrm{OD}_{600}\right.$ of $\left.\sim 0.8\right)$ were harvested by centrifugation ( $3 \mathrm{~min}, 15,000 \mathrm{xg}$ ), washed twice with $100 \mathrm{mM}$ potassium phosphate buffer ( $\mathrm{pH}$ 8.0). Cells were resuspended in $100 \mathrm{mM}$ potassium phosphate buffer containing $50 \mathrm{mM} \mathrm{KCl}$ and sonicated at $4^{\circ} \mathrm{C}$ for 2 minutes (10 sec at a time, and until $2 \mathrm{~min}$ ). After centrifugation ( $3 \mathrm{~min}, 15000 \mathrm{xg}$ ) the supernatant was kept at low temperature $\left(4^{\circ} \mathrm{C}\right)$ or in ice. The catalytic activity of intracellular GDH was determined at room temperature by measuring the reduction of $\mathrm{NAD}^{+}$to the substrate-dependent absorbance change of $\mathrm{NAD}(\mathrm{H})$ at $340 \mathrm{~nm}(\varepsilon 340=6.22 \mathrm{mM}-1 \mathrm{~cm}-1)$ using the method described by Ahrens et al. [6], Raj et al. [3], Gonzalez et al. [4] and Ashok et al. [2] with slight modifications. The enzyme assay was performed in triplicates, and the $1 \mathrm{ml}$ reaction mixture contains $50 \mathrm{mM}$ potassium phosphate buffer ( $\mathrm{pH} 8.0$ ), $30 \mathrm{mM}$ ammonium sulfate, $0.2 \mathrm{M}$ glycerol and $1.2 \mathrm{mM}$ NAD. The assay was initiated by adding $50 \mu \mathrm{l}$ of cell extract 
in $250 \mu \mathrm{l}$ reaction mixture, and the absorbance increase (NADH) was followed with a spectrophotometer for 3-5 minutes. One unit of activity is the amount of enzyme required to reduce $1 \mu$ mole of substrate per minute. The specific activity of GDH is expressed as $\mu$ moles of substrate/minute/mg of cell protein and represent averages for at least three cell preparations. The protein concentration was determined by using the Bradford method [25], and bovine serum albumin served as the standard protein.

\section{Adapted mutant development}

The selected strain SRP3 was used to progressively develop adapted mutant strains that withstood 100, 125, 150, 175 and $200 \mathrm{~g} / \mathrm{L}$ glycerol concentrations. The six-tube subculture-generations of evolutionary technique was used to achieve mutant [26]. This adaptive evolutionary technique involved sub-culturing the organism six consecutive times in tubes of MS medium containing $2.5 \mathrm{~g} / \mathrm{L}$ yeast extract, the same glycerol at the same concentration and culturing conditions. The glycerol concentration was increased, and the subculture generations were repeated. The adapted strain labeled as SRM3 was obtained that grew in $200 \mathrm{~g} / \mathrm{L}$ glycerol by increasing the concentration of glycerol and repeating the six subculture generations.

\section{Analytical methods}

Cell growth and GDH enzyme activity were measured as optical density (OD) at 600 and $340 \mathrm{~nm}$ respectively using microplate spectrophotometer $(\mathrm{EPOCH}$, BioTek). The cell dry weight was calculated from the optical density $\left(\mathrm{OD}_{600}\right)$ using a standard curve (calibration curve) for this bacterial strain.

The $\mathrm{pH}$ values of the culture broth were determined using AB15 $\mathrm{pH}$ meter (Fisher Scientific). After confirming the identity of the products by GC-MS (Varian 1200 Quadrupole GC/MS using helium as the carrier gas), the concentrations (g/L) of glycerol, 2,3-BD, 1,3-PDO, acetic acid, acetoin etc. were determined using gas chromatograph GC 14A (Shimatzu Corp., Kyoto, Japan) equipped with a flame ionization detector and DB-WAXetr column. The column temperature was set to range from $45^{\circ} \mathrm{C}$ to $240{ }^{\circ} \mathrm{C}$; whereas, the injector and detector temperature was $250{ }^{\circ} \mathrm{C}$. The carrier gas was nitrogen. About $1.5 \mathrm{ml}$ of culture broth (fermented broth) was taken after $0,24,48,72,96$, 120 and $144 \mathrm{~h}$ of incubation. All the samples tested herein were purified immediately by centrifugation at $15,000 \mathrm{xg}$ at $4{ }^{\circ} \mathrm{C}$ for $5 \mathrm{~min}$ (accu Spin Micro 17, Fisher Scientific). The supernatants were filtered through membrane filter $(0.45 \mu \mathrm{m}$ pores size $)$, and frozen for later GC-FID analyses. The purified samples except $0 \mathrm{~h}$ incubation were diluted 5-10 times with distilled (Milli Q) water, and then injected $1 \mu \mathrm{l}$ into GC. The results are presented as the means of three independent experiments.

Gene Bank accession No: The gene Bank accession number of the sequence reported in this paper is KR092086

\section{Results}

\section{Strain isolation and identification}

A number of bacterial strains were isolated from soil and paper mill waste samples with the goal of isolating strains able to utilize glycerol as a sole carbon source to produce GDH enzyme under aerobic condition. Under our experimental conditions the strain SRP3 (K. variicola) isolated from paper mill waste displayed significant GDH activity. This isolated strain SRP3 was identified using 16S rRNA gene sequencing. Sequence alignment in NCBI revealed a $99 \%$ similarity to the sequence of the strains K. variicola DSM 15968 or K. variicola KSM-005 or K. variicola MMUST-005, and then the species $K$. variicola (strain $K$. variicola SRP3) was identified by its morphological and physiological properties (Table 1). The strain was found to grow well on LB agar, yielding large mucoid colonies. Light microscopy revealed rod-shaped and encapsulated cells, arrange singly/ in pair/ in short chain, 0.3-1.0 $\mu \mathrm{m}$ in diameter and 0.6-6.0 in length. The very strain reported in this paper has been designated as Klebsiella variicola SRP3, and its GenBank accession No. was released as KR092086.

\section{Effect of temperature, incubation time, medium ingredient and $\mathrm{pH}$ on enzyme activity}

Glycerol dehydrogenase (GDH) is a key enzyme in oxidative pathway for aerobic bioconversion of glycerol. To optimize the incubation temperature and time for maximum enzyme activity, experiments were performed in batch fermentation processes without $\mathrm{pH}$ control (starting pH 7.0) at $25,30,35$ and $40^{\circ} \mathrm{C}$. The MS medium containing glycerol $(50 \mathrm{~g} / \mathrm{L})$ and yeast extract $(2.5 \mathrm{~g} / \mathrm{L})$ was used for growth of the bacterium. The maximum enzyme activity (347.33 units/ mg protein) was attained at $35^{\circ} \mathrm{C}$ and $72 \mathrm{~h}$ incubation time (Figure 2).

In our study glycerol is only the substrate and yeast extract is the nitrogen source of GDH enzyme production. For optimization of glycerol and yeast extract concentrations, three different concentrations $(20 \mathrm{~g} / \mathrm{L}, 50 \mathrm{~g} / \mathrm{L}$ and $75 \mathrm{~g} / \mathrm{L})$ of glycerol, and three different concentrations $(1.0 \mathrm{~g} / \mathrm{L}, 2.5 \mathrm{~g} / \mathrm{L}$ and $5 \mathrm{~g} / \mathrm{L})$ of yeast extract were used respectively. The results showed that $50 \mathrm{~g} / \mathrm{L}$ glycerol and $2.5 \mathrm{~g} / \mathrm{L}$ yeast extract were the favorable carbon and nitrogen sources for enzyme activity at $35^{\circ} \mathrm{C}$ after 24,48 and $72 \mathrm{~h}$ of incubation (Figure 3 ).

The influence of $\mathrm{pH}$ on GDH and cell growth in the batch bioprocess without $\mathrm{pH}$ control was significant (Table 2 and Figure 4). For optimization of $\mathrm{pH}$, the initial (starting) $\mathrm{pH}$ values of the culture medium were adjusted to set point by adding $1 \mathrm{M} \mathrm{NaOH} / \mathrm{HCl}$ before autoclaving. The time profiles of $\mathrm{pH}$ changes, and the production of cell biomass with different starting $\mathrm{pH}$ are shown in Table 2. However, the results of enzyme activity under shake-flask fermentation with

\begin{tabular}{|c|c|c|c|}
\hline Characters & Results & $\begin{array}{l}\text { Expected results } \\
\text { for } K \text {. variicola }\end{array}$ & $\begin{array}{l}\text { Results related to the } \\
\text { sp. of Klebsiella }\end{array}$ \\
\hline Gram staining & Gram - & + & All species \\
\hline Capsule & + & + & All species \\
\hline Indole production & - & - & All sp. except $K$. oxytoca \\
\hline $\mathrm{H}_{2} \mathrm{~S}$ production & - & - & All species \\
\hline Methyl red & - & - & $\begin{array}{l}\text { K. oxytoca and } K \text {. } \\
\text { pneumoniae }\end{array}$ \\
\hline Voges-Proskauer & + & + & $\begin{array}{l}\text { K. oxytoca, K. planticola } \\
\text { and K. pneumoniae }\end{array}$ \\
\hline Citrate & + & + & $\begin{array}{l}\text { K. oxytoca, K. planticola } \\
\text { and K. pneumoniae }\end{array}$ \\
\hline Urea hydrolysis & + & + & $\begin{array}{l}\text { K. oxytoca and } K . \\
\text { planticola }\end{array}$ \\
\hline Gas/acid from Lactose & + & + & $\begin{array}{l}\text { K. oxytoca and } K \text {. } \\
\text { pneumoniae }\end{array}$ \\
\hline Gas/acid from glucose & + & + & $\begin{array}{l}\text { K. pneumoniae and } K \text {. } \\
\text { oxytoca }\end{array}$ \\
\hline Lysine decarboxilate & + & + & $\begin{array}{l}\text { K. oxytoca, K. planticola } \\
\text { and K. pneumoniae }\end{array}$ \\
\hline Oxidase & - & - & All species \\
\hline Catalase & + & + & All species \\
\hline Adonitol fermentation & - & - & $\begin{array}{l}\text { K. oxytoca, K. planticola } \\
\text { and K. pneumoniae }\end{array}$ \\
\hline Rhamnose fermentation & + & + & $\begin{array}{l}\text { Negative to all other } \\
\text { species }\end{array}$ \\
\hline
\end{tabular}

Table 1: Morphological and physiological characters of strain K. variicola SRP3 


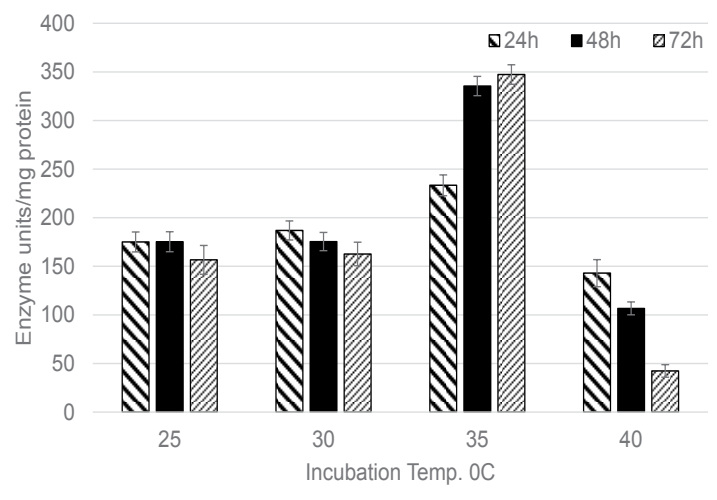

Figure 2: Effect of incubation temperature on specific activity of enzyme of strain SRP3 in batch process, minimal salt (MS) medium supplemented with yeast extract $0.25 \%$ and glycerol $5.0 \%$, stating $\mathrm{pH} 7.0$ and incubation temperature $35^{\circ} \mathrm{C}$.

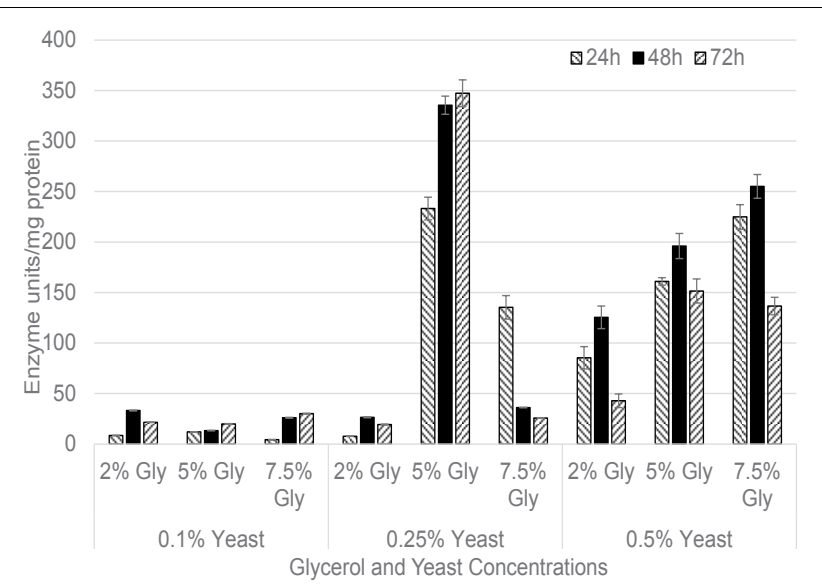

Figure 3: Effect of glycerol and yeast extract concentration on enzyme activity of SRP3 strain, minimal salt (MS) medium supplemented with different concentrations of glycerol and yeast extract, stating $\mathrm{pH} 7.0$ and incubation temperature $35^{\circ} \mathrm{C}$.

various pHs ranging from 4.0 to 9.0 are presented in Figure 4. Low and higher $\mathrm{pH}$ inhibited cell growth and GDH production. However a $\mathrm{pH}$ higher than 7.0, a similar phenomenon was observed. At a $\mathrm{pH}$ 5.0, the cell growth and enzyme production were increased. As shown in Figure 4 and Table 2, the maximum enzyme activity and cell growth were obtained at $\mathrm{pH}$ 5.0. Interestingly, the $\mathrm{pH}$ of the medium was sharply dropped from starting $\mathrm{pH}(5.0,6.0,7.0,8.0$ and 9.0) after $24 \mathrm{~h}$ of incubation and reached values between 4.48 and 4.68 . On the other hand, the medium $\mathrm{pH}$ was increased from $\mathrm{pH} 4.0$ to 4.39 . This incubation period is the exponential growth phase of the batch culture and the $\mathrm{pH}$ was dropped due to the production of acetate in the culture medium.

After optimized yeast extract and glycerol concentrations, the effects of five other nitrogen sources $(5 \mathrm{~g} / \mathrm{L})$ on GDH activity were also investigated in this study, which included peptone, malt, $\left(\mathrm{NH}_{4}\right)_{2} \mathrm{SO}_{4}$, $\mathrm{NH}_{4} \mathrm{Cl}$ and $\mathrm{NH}_{4} \mathrm{NO}_{3}$. MS medium with supplementary carbon and nitrogen sources was used throughout the experiments. As shown in Figure 5, peptone and malt extract showed the highest enzyme activity compared to that of other nitrogen sources. Although, the price of peptone is too high for bulk fermentative products, it is extensively used as an ideal medium for bacterial growth. That is why here we investigated the influence of peptone concentration on GDH enzyme.
In case of peptone, the maximum enzyme activity (421.82 units/mg protein) was obtained at a concentration of $5 \mathrm{~g} / \mathrm{L}$ after $72 \mathrm{~h}$ (Figure 6).

\section{Batch fermentation under optimized conditions}

After optimized conditions for maximizing GDH activity, batch fermentations were performed in fermentation medium at $\mathrm{pH} 5.0$, temperature $35^{\circ} \mathrm{C}$, glycerol $50 \mathrm{~g} / \mathrm{L}$, yeast extract $2.5 \mathrm{~g} / \mathrm{L}$ and peptone 5 $\mathrm{g} / \mathrm{L}$ for quantification of bio-products. Under the above fermentation conditions, two major products viz., 2,3-BD and 1,3-PDO, and some minor products including acetoin, acetate, lactate and succinate were obtained after $24 \mathrm{~h}$ of incubation. The product 2,3-BD obtained from optimized condition was a mixture of meso-2,3-BD and SS-2,3-BD.

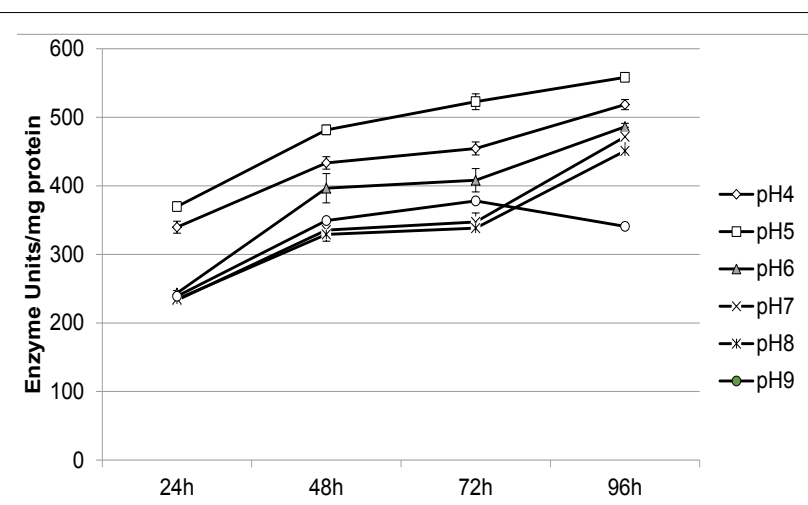

Figure 4: Influence of initial $\mathrm{pH}$ on enzyme activity of SRP3 without $\mathrm{pH}$ control, incubation temperature $350 \mathrm{C}$, minimal salt (MS) medium supplemented with glycerol $5.0 \%$ and yeast extract $2.5 \%$, and incubation temperature was $35{ }^{\circ} \mathrm{C}$.

\begin{tabular}{|c|c|c|c|c|c|c|c|c|}
\hline \multirow{2}{*}{$\begin{array}{c}\text { Initial } \\
\text { pH }\end{array}$} & \multicolumn{4}{|c|}{$\begin{array}{c}\text { Biomass }\left(O D_{600 \mathrm{~nm}}\right) \text { of the Culture } \\
\text { broth }\end{array}$} & \multicolumn{4}{|c|}{${ }^{*}$ Final $\mathrm{pH}$ of the fermented broth } \\
\hline & $24 h$ & $48 \mathrm{~h}$ & $72 \mathrm{~h}$ & $96 h$ & $24 \mathrm{~h}$ & $48 \mathrm{~h}$ & $72 \mathrm{~h}$ & $96 \mathrm{~h}$ \\
\hline 4.0 & 0.747 & 0.855 & 1.021 & 1.137 & 4.39 & 4.45 & 4.47 & 4.58 \\
\hline 5.0 & 0.789 & 0.994 & 1.126 & 1.314 & 4.48 & 4.47 & 4.52 & 4.78 \\
\hline 6.0 & 0.713 & 0.973 & 1.073 & 1.222 & 4.57 & 4.52 & 4.56 & 4.77 \\
\hline 7.0 & 0.780 & 0.919 & 1.071 & 1.202 & 4.61 & 4.61 & 4.76 & 4.84 \\
\hline 8.0 & 0.746 & 0.933 & 1.123 & 1.198 & 4.57 & 4.57 & 4.64 & 4.72 \\
\hline 9.0 & 0.766 & 0.916 & 1.131 & 1.197 & 4.68 & 4.68 & 4.73 & 4.62 \\
\hline
\end{tabular}

Table 2: Effect of pH on cell growth after 24, 48, 72 and 96 hours of incubation at $35^{\circ} \mathrm{C}$ of the bacterial strain $K$. variicola SRP3.

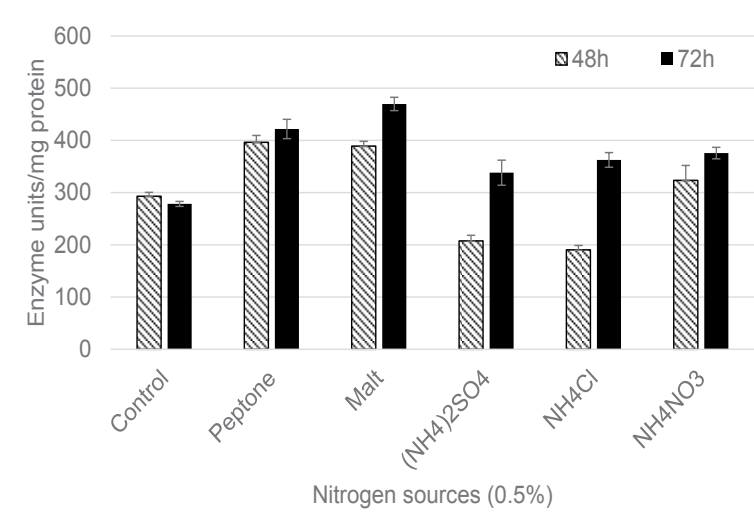

Figure 5: Effect of nitrogen sources on enzyme activity of strain SRP3, minimal salt (MS) medium supplemented with glycerol $5.0 \%$ and yeast extract $0.25 \%$, stating $\mathrm{pH} 7.0$ and incubation temperature $35^{\circ} \mathrm{C}$. 

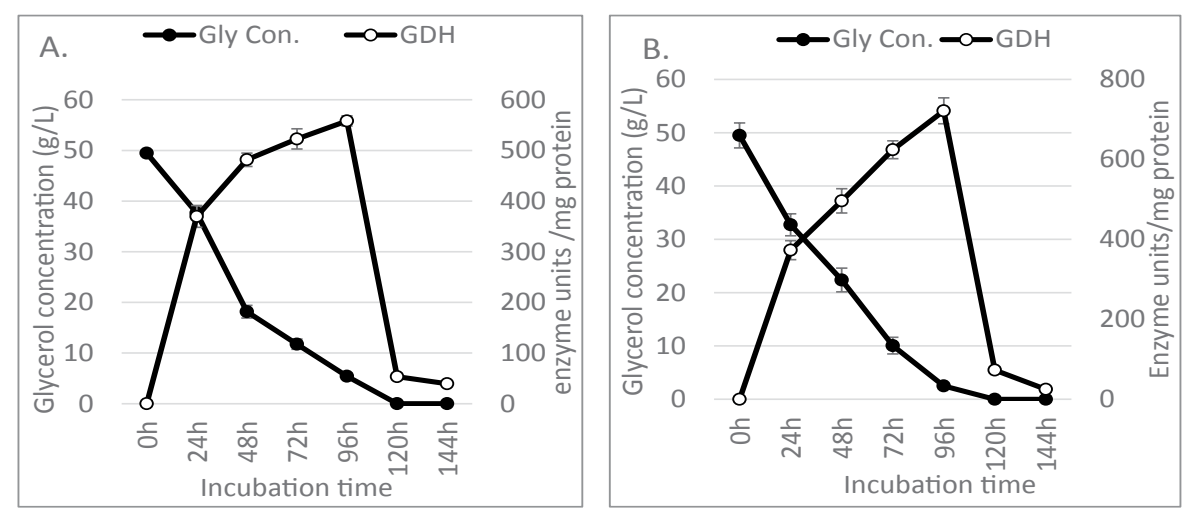

Figure 6: Glycerol consumption and specific activity of GDH by SRP3 (A) and SRM3 (B) in fermentation medium at initial pH 5.0 and incubation temperature $35^{\circ} \mathrm{C}$.

Figure 7 shows a typical profile for the fermentation of glycerol by the wild type strain SRP3 at different incubation time and accumulation of major products. The maximum product concentrations were achieved from 96 to $120 \mathrm{~h}$ incubation. After $120 \mathrm{~h}$ incubation the glycerol $(50$ $\mathrm{g} / \mathrm{L})$ was completely consumed, and the concentration of major principal product 2,3-PDO was $25.07 \pm 0.60 \mathrm{~g} \mathrm{~L}^{-1}$. The other bioproducts determined in the culture broth were $1,3-\mathrm{BD}$, acetoin and acetic acid, with concentrations, $7.62 \pm 0.75 \mathrm{~g} \mathrm{~L}^{-1}, 2.81 \pm 0.23 \mathrm{~g} \mathrm{~L}^{-1}$ and $0.82 \pm 0.09 \mathrm{~g} \mathrm{~L}^{-1}$ respectively. The highest concentration of 2,3PDO obtained after $96 \mathrm{~h}$ was $25.33 \pm 0.90 \mathrm{~g} \mathrm{~L}^{-1}$. However, the highest concentration of 1,3-PDO, acetoin, acetic acid, lactic acid, succinic acid and oxalic acid obtained after $144 \mathrm{~h}$ were $7.82 \pm 0.83 \mathrm{~g} \mathrm{~L}^{-1}, 8.47 \pm 0.23$ $\mathrm{g} \mathrm{L}^{-1}, 0.85 \pm 0.07 \mathrm{~g} \mathrm{~L}^{-1}, 0.77 \pm 0.04 \mathrm{~g} \mathrm{~L}^{-1}, 0.98 \pm 0.06 \mathrm{~g} \mathrm{~L}^{-1}$ and $0.56 \pm$ $0.04 \mathrm{~g} \mathrm{~L}^{-1}$ respectively. The productivity of the whole process for the four major products (2,3-BD, 1,3-PDO, acetoin and acetate) was about $0.37 \mathrm{~g} \mathrm{~L}^{-1} \mathrm{~h}^{-1}$ after $96 \mathrm{~h}$. The main bio-products of SRP3 were 2,3-BD, 1,3-PDO and acetoin, with extraordinarily little acetic acid, succinate, lactate and oxalic acid accumulation. Nevertheless, the Figure 8 shows that $K$. variicola SRM3, the adapted mutant strain of SRP3 reported this article, used $100 \%$ glycerol within $120 \mathrm{~h}$, producing $23.36 \pm 1.04 \mathrm{~g} \mathrm{~L}^{-1}$ 2,3-BD, $7.52 \pm 0.96 \mathrm{~g} \mathrm{~L}^{-1} 1$,3-PDO, $10.19 \pm 0.76 \mathrm{~g} \mathrm{~L}^{-1}$ acetoin, $1.06 \pm 0.06$ $\mathrm{g} \mathrm{L}^{-1}$ acetate, $0.96 \pm 0.05 \mathrm{~g} \mathrm{~L}^{-1}$ lactate and $0.88 \pm 0.06 \mathrm{~g} \mathrm{~L}^{-1}$ succinate. The highest concentration of 2,3-BD obtained after $96 \mathrm{~h}$ incubation was $29.87 \pm 1.54 \mathrm{~g} \mathrm{~L}^{-1}$. However the yields of 2,3-BD, 1,3-PDO and acetoin after $96 \mathrm{~h}$ incubation were $0.6,0.15$ and $0.04 \mathrm{~g} / \mathrm{g}$ respectively (Table 3 ). This adapted strain is capable to grow in a very high glycerol concentration, up to $200 \mathrm{~g} / \mathrm{L}$. This demonstrated that the mutated strain is better adapted to utilize glycerol and effectually convert it to $2,3-\mathrm{BD}$, 1,3-PDO and acetoin than the wild strain.

We tried to keep the $\mathrm{pH}$ stable and neutralize acid in the culture medium during fermentation process. The citrate buffer ( $\mathrm{pH} 4.8)$ and $\mathrm{CaCO}_{3}(2 \% \mathrm{v} / \mathrm{w})$ were used in the culture medium to keep the $\mathrm{pH}$ stable and neutralize acid respectively (Table 3 ). The Comparison between the final concentrations of major products and conversion yields of glycerol utilization by wild type K. variicola SRP 3 and its adapted mutant SRM3, obtained in batch process is shown in Table 3. The adapted mutant strain K. variicola SRM3 utilized 97.5\% glycerol within $96 \mathrm{~h}$ incubation.

\section{Discussion}

Anaerobically many microorganisms are able to utilize glycerol as a sole carbon source, and the use of these microorganisms has increased attention for the bioconversion of glycerol [27]. Due to lake of external electron acceptor microbial growth is hampering in anaerobic condition. To date, several attempts have been made to biotechnologically produce value-added products viz., 1,2PDO, 1,3-PDO and $\mathrm{H}_{2}$ from low priced glycerol using anaerobic or microaerophilic fermentation process $[28,29]$ but very little work have been done on aerobic process. Microaerophilic Klebsiella pneumoniae strains are also practical candidates for bio-fermentation process to produce bio-products $[19,21]$. Considering the aerobic bioconversion of glycerol to biofuels and value-added bio-products, our aim was to isolate novel strains for efficient product yield. Because, there were no available effectual strains designated nor was there rationality about the strain's requirement for successful production of 1,3-PDO and 2,3-BD from glycerol under aerobic process.

Recently, it was reported that Klebsiella could produce 1,3-PDO anaerobically [30] and 2,3-BD aerobically [12]. Still now there is no any report for the bioconversion of glycerol by K. variicola. Our new isolated strain $K$. variicola SRP3 could utilize glycerol as a sole carbon and energy source for their growth, and produce significant amount of numerous industrially important products under aerobic condition through GDH dependent oxidative pathway. Our report indicated that the batch fermentation with initial glycerol $50 \mathrm{~g} / \mathrm{L}$ was the optimal concentration for maximum GDH activity which is the highest glycerol concentration in batch culture till now (Figure 2). Recently, Petrov and Petrova [12] reported the highest product yield $48.47 \%$ of 2,3 -BD in feed batch fermentation. They also claimed that this amount was the highest reported till now. Furthermore, under optimized conditions in our study, the product yield 59.8\% (29.9 g/50.0 g glycerol) of 2,3BD was achieved by a adapted novel strain $K$. variicola SRM3 was the highest amount and reported till now. The results reported in Figure 6, which supported that the GDH activity and fermentation process were decreased after $96 \mathrm{~h}$ due to some product inhibition as well as depletion of glycerol concentration in the medium in aerobic batch fermentation condition. The strain $K$. variicola SRP3 reported herein exhibited $100 \%$ of glycerol consumption after $120 \mathrm{~h}$. This research viewed that the higher glycerol concentration, up until about $50 \mathrm{~g} / \mathrm{L}$ of feedstock concentration showed maximum production of reported end products which could be the new prospect of glycerol bioconversion field.

Our current study indicates that the GDH enzyme played a vital role to catalyze the primary step of glycerol oxidation which is responsible for glycerol utilization in $K$. variicola. This GDH enzyme is a key component in oxidative pathway of glycerol metabolism, and 2,3-BD, 1,3-PDO and acetoin formation in $K$. variicola. These findings recommended that the GDH enzyme might have dynamic 
physiological consequence to the microbes when glycerol as carbon source was used. In addition, the role of proper environmental conditions like incubation temperature, nitrogen source, $\mathrm{pH}$ etc. in this strain might also contribute to the GDH over expression and favor

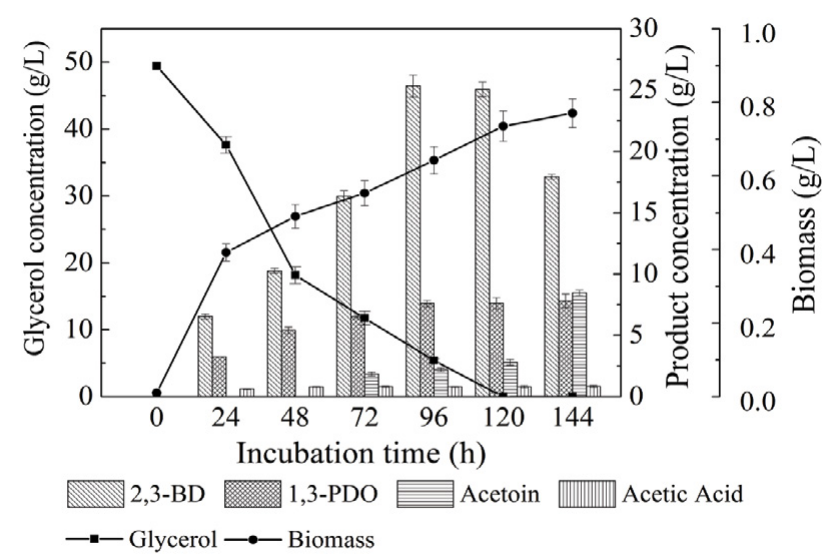

Figure 7: Production kinetics of major products obtained by $K$. variicola SRP3 in fermentation medium without $\mathrm{pH}$ control, starting $\mathrm{pH} 5.0$ and incubation temperature was $35^{\circ} \mathrm{C}$.

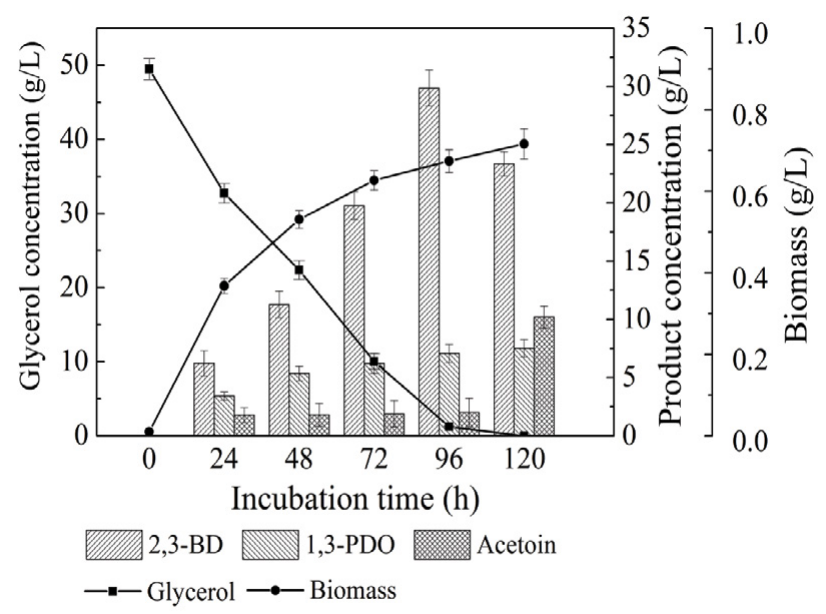

Figure 8: Production kinetics of major products obtained by adapted strain $K$. variicola SRM3 in fermentation medium without $\mathrm{pH}$ control, started at $\mathrm{pH} 5.0$, incubation temperature $35^{\circ} \mathrm{C}$. the survival of this strain on glycerol by shifting glycerol metabolism from DHA to the formation of other compounds. Our results also suggested the establishment of optimal conditions for 2,3-BD, 1,3PDO and acetoin synthesis must include enhancement of the GDH activity through oxidative pathway of the bioconversion of glycerol. In oxidative pathway, glycerol is dehydrogenated, phosphorylated, and directed towards the glycolysis, generating a variety of end products, including 2,3-BD, ethanol, DHA, acetate and acetoin. However, we attained 2,3-BD as a final major product, and 1,3-PDO, acetoin and acetic acid as the minor products.

Our research paper reported a role of GDH involved in oxidative pathway of glycerol metabolism and some important metabolites (2,3-BD, 1,3-PDO and acetoin) formation in a novel bacterial strain $K$. variicola SRP3. The GDH was over expressed, and this new strain promises to be a better organism for the bio-conversion of glycerol to value-added products.

For scale up 2,3-BD product concentration up to industrial level we need to develop the strain and optimize fermentation conditions. Crude glycerol (biodiesel waste) contains methanol, salts, soaps, nonglycerol organic matter, and catalysts as the main impurities which can negatively influence the bioconversion process. Moreover, some acid byproducts like acetate, lactate and succinate inhibit of 2,3-BD production [31]. To overcome this problem, the strain should be developed by mutagenesis [32]. Thus, further work is required to obtain the highly efficient strain by mutagenesis for the utilization of crude glycerol and yield of the end product 2,3-BD by this $K$. variicola SRP3 strain. Bioreactor and optimized process parameters should be used to scale up product concentration for economic feasibility for mass bio-production of 2,3-BD from biodiesel waste glycerol. The strain $K$. variicola produced 2,3-BD, along with a number of by-products included some organic acids. 2,3-BD can be recovered from the fermentation broth using alcohol precipitation and vacuum distillation process proposed by Jeon et al. [33]. Briefly, the cells are removed from the fermentation broth by centrifugation and filtration. The cell-free fermented broth is concentrated to around $500 \mathrm{~g} / \mathrm{L}$ of 2,3-BD by vacuum evaporation at $50^{\circ} \mathrm{C}$ and $50 \mathrm{mbar}$ vacuum pressure. For precipitation of organic acids and inorganic salts, concentrated solution is further treated with light alcohols like methanol, ethanol, and isopropanol. At the last step, a vacuum distillation process empowered the recovery of $76.2 \%$ of the treated $2,3-\mathrm{BD}$, with $96.1 \%$ purity.

\begin{tabular}{|c|c|c|c|c|c|c|c|c|c|c|}
\hline \multirow{2}{*}{ Strains (Medium) } & \multirow{2}{*}{ Initial pH } & \multirow{2}{*}{ Final $\mathrm{pH}$} & \multirow{2}{*}{ Biom. (g/L) } & \multirow{2}{*}{$\begin{array}{c}\text { Glycerol } \\
\text { utilized (\%) }\end{array}$} & \multicolumn{2}{|c|}{ 2,3-BD } & \multicolumn{2}{|c|}{ 1,3-PDO } & \multicolumn{2}{|c|}{ Acetoin } \\
\hline & & & & & Concen. (g/L) & Yielda $^{a}(\mathbf{g} / \mathbf{g})$ & Concen. (g/L) & Yielda $^{a}(\mathbf{g} / \mathbf{g})$ & Concen. (g/L) & Yield $^{\mathrm{a}}(\mathrm{g} / \mathrm{g})$ \\
\hline SRP3 (M) & 5.0 & 4.84 & 0.64 & 88.0 & $25.3 \pm 0.90$ & 0.58 & $7.6 \pm 0.26$ & 0.17 & $2.2 \pm 0.15$ & 0.05 \\
\hline SRP3 (MC) & 7.0 & 5.46 & 0.64 & 84.0 & $23.1 \pm 1.02$ & 0.55 & $7.1 \pm 0.34$ & 0.17 & $1.8 \pm 0.2$ & 0.04 \\
\hline SRP3 (MCB) & 4.8 & 4.94 & 0.61 & 79.0 & $26.0 \pm 0.98$ & 0.59 & $6.9 \pm 0.44$ & 0.17 & $2.5 \pm 0.31$ & 0.06 \\
\hline SRM3(M) & 5.0 & 4.90 & 0.67 & 97.5 & $29.9 \pm 1.54$ & 0.60 & $7.08 \pm 1.22$ & 0.15 & $2.0 \pm 0.78$ & 0.04 \\
\hline
\end{tabular}

All experimental points presented are mean values from triplicate experiments;

Biom. Dry weight of biomass

Concen. Concentration

M Minimal salt medium with glycerol $5 \%$, yeast extract $0.25 \%$ and peptone $0.5 \%$

MC M with $\mathrm{CaCo}_{3} \%$

MCB M with citrate buffer

aProduct $(\mathrm{g})$ obtained from bioconversion of per gram glycerol in batch fermentation

Table 3: Comparison between the final concentrations of major products and conversion yields of glycerol utilization at initial concentration $50 \mathrm{~g} / \mathrm{L}$ under un-controlled $\mathrm{pH}$ condition by wild type SRP3 and its mutant SRM3, obtained in batch process after $96 \mathrm{~h}$ incubation at $37^{\circ} \mathrm{C}$. 
Citation: Rahman MS, Yuan Z, Ma K, Xu CC, Qin W (2015) Aerobic Conversion of Glycerol to 2,3-Butanediol by a Novel Klebsiella variicola SRP3 Strain. J Microb Biochem Technol 7: 299-304. doi:10.4172/1948-5948.1000229

\section{References}

1. Schneider SH (1989) The greenhouse effect: science and policy. Science 243 771-781.

2. Ashok S, Mohan Raj S, Ko Y, Sankaranarayanan M, Zhou S, et al. (2013) Effect of puuC overexpression and nitrate addition on glycerol metabolism and anaerobic 3-hydroxypropionic acid production in recombinant Klebsiella pneumoniae Î"glpKÎ"dhaT. Metab Eng 15: 10-24.

3. Raj SM, Rathnasingh C, Jung WC, Selvakumar E, Park SH (2010) A nove NAD+-dependent aldehyde dehydrogenase encoded by the puuC gene of Klebsiella pneumoniae DSM 2026 that utilizes 3-hydroxypropionaldehyde as a substrate. Biotechnol Bioprocess Eng 15: 131-138.

4. Gonzalez R, Murarka A, Dharmadi Y, Yazdani SS (2008) A new model for the anaerobic fermentation of glycerol in enteric bacteria: trunk and auxiliary pathways in Escherichia coli. Metab Eng 10: 234-245.

5. Hao J, Lin R, Zheng Z, Liu H, Liu D (2008) Isolation and characterization of microorganisms able to produce ,3-propanediol under aerobic conditions. World J Microbiol Biotechnol 24:1731-1740.

6. Ahrens K, Menzel K, Zeng A, Deckwer W (1998) Kinetic, dynamic, and pathway studies of glycerol metabolism by Klebsiella pneumoniae in anaerobic continuous culture: III. Enzymes and fluxes of glycerol dissimilation and ,3-propanediol formation. Biotechnol Bioeng 59: 544-52.

7. Celi $\AA$ „ska E (2010) Debottlenecking the ,3-propanediol pathway by metabolic engineering. Biotechnol Adv 28: 519-530.

8. Huang M, Oppermann-Sanio FB, Steinbüchel A (1999) Biochemical and molecular characterization of the Bacillus subtilis acetoin catabolic pathway. J Bacteriol 181: 3837-3841.

9. López JM, Thoms B, Rehbein H (1975) Acetoin degradation in Bacillus subtilis by direct oxidative cleavage. Eur J Biochem 57: 425-430.

10. Xiao Z, Wang X, Huang Y, Huo F, Zhu X, et al. (2012) Thermophilic fermentation of acetoin and ,3-butanediol by a novel Geobacillus strain. Biotechnol Biofuels 5: 88.

11. Ji XJ, Huang H, Ouyang PK (2011) Microbial ,3-butanediol production: a stateof-the-art review. Biotechnol Adv 29: 351-364.

12. Petrov K, Petrova $P$ (2010) Enhanced production of ,3-butanediol from glycerol by forced $\mathrm{pH}$ fluctuations. Appl Microbiol Biotechnol 87: 943-949.

13. Rao B, Zhang LY, Sun J, Su G, Wei D, et al. (2012) Characterization and regulation of the ,3-butanediol pathway in Serratia marcescens. Appl Microbiol Biotechnol 93: 2147-2159.

14. Yang TH, Rathnasingh C, Lee HJ, Seung D2 (2014) Identification of acetoin reductases involved in ,3-butanediol pathway in Klebsiella oxytoca. J Biotechnol 172: 59-66.

15. Hao J, Xu F, Liu H, Liu D (2006) Downstream processing of ,3-propanedio fermentation broth. J Chem Technol Biotechnol 81: 102-108.

16. Knifton JF, James TG, Slaugh LH, Allen KD, Weider PR, et al. (2004) One-step production of ,3-propanediol from ethylene oxide and syngas with a cobalt-iron catalyst. United States Patent 6750373.
17. Biebl H, Marten S (1995) Fermentation of glycerol to ,3-propanediol: use of cosubstrates. Appl Microbiol Biotechnol 44:15-19.

18. Yazdani SS, Gonzalez R (2007) Anaerobic fermentation of glycerol: a path to economic viability for the biofuels industry. Curr Opin Biotechnol 18: 213-219.

19. Biebl H, Zeng AP, Menzel K, Deckwer WD (1998) Fermentation of glycerol to ,3-propanediol and ,3-butanediol by Klebsiella pneumoniae. Appl Microbiol Biotechnol 50: 24-29.

20. Jarvis GN, Moore ER, Thiele JH (1997) Formate and ethanol are the major products of glycerol fermentation produced by a Klebsiella planticola strain isolated from red deer. J Appl Microbiol 83: 166-174.

21. Zheng ZM, Xu YZ, Liu HJ, Guo NN, Cai ZZ, et al. (2008) Physiologic mechanisms of sequential products synthesis in ,3-propanediol fed-batch fermentation by Klebsiella pneumoniae. Biotechnol Bioeng 100: 923-932.

22. Alves MS, Dias RC, de Castro AC, Riley LW, Moreira BM (2006) Identification of clinical isolates of indole-positive and indole-negative Klebsiella spp. J Clin Microbiol 44: 3640-3646.

23. Holt JG, Krieg NR, Sneath PHA, Staley JT, Williams ST (1994) Bergey's manual of determinative bacteriology, 9th edition, Baltimore, Maryland.

24. Rosenblueth M, Martínez L, Silva J, Martínez-Romero E (2004) Klebsiella variicola, a novel species with clinical and plant-associated isolates. Syst Appl Microbiol 27: 27-35.

25. Bradford MM (1976) A rapid and sensitive method for the quantitation of microgram quantities of protein utilizing the principle of protein-dye binding. Anal Biochem 72: 248-254

26. Nwachukwu R, Shahbazi A, Wang L, Ibrahim S, Worku M, et al. (2012) Bioconversion of glycerol to ethanol by a mutant Enterobacter aerogenes. AMB Express 2: 20 .

27. da Silva GP, Mack M, Contiero J (2009) Glycerol: a promising and abundant carbon source for industrial microbiology. Biotechnol Adv 27: 30-39.

28. Ito T, Nakashimada Y, Senba K, Matsui T, Nishio N (2005) Hydrogen and ethanol production from glycerol-containing wastes discharged after biodiese manufacturing process. J Biosci Bioeng 100: 260-265.

29. Jensen TO, Kvist T, Mikkelsen MJ, Christensen PV, Westermann P (2012) Fermentation of crude glycerol from biodiesel production by Clostridium pasteurianum. J Ind Microbiol Biotechnol 39: 709-717.

30. Xu YZ, Guo NN, Zheng ZM, Ou XJ, Liu HJ, et al. (2009) Metabolism in ,3-propanediol fed-batch fermentation by a D-lactate deficient mutant of Klebsiella pneumoniae. Biotechnol Bioeng 104: 965-972.

31. Converti A, Perego P, Del Borghi M (2003) Effect of specific oxygen uptake rate on Enterobacter aerogenes energetics: carbon and reduction degree balances in batch cultivations. Biotechnol Bioeng 82: 370-377.

32. Ji XJ, Huang H, Li S, Du J, Lian M (2008) Enhanced ,3-butanediol production by altering the mixed acid fermentation pathway in Klebsiella oxytoca. Biotechnol Lett 30: 731-734.

33. Jeon S, Kim DK, Song H, Lee HJ, Park S, et al. (2014) 3-Butanediol recovery from fermentation broth by alcohol precipitation and vacuum distillation. J Biosci Bioeng 117: 464-470. 